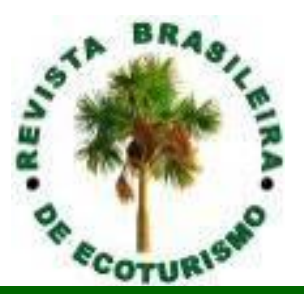

\title{
Parque Estadual da Serra do Conduru: perfil, percepções e sugestões dos visitantes
}

\section{State Park of Serra do Conduru: profile, perceptions and suggestions of visitors}

\author{
Marco Aurélio Avila, Claudio Damião Rosa
}

\section{RESUMO}

Unidades de Conservação (UCs) colaboram com a preservação da biodiversidade, manutenção da água e do clima, e oferecem oportunidades para experiências prazerosas em contato com a natureza. No presente estudo, nós analisamos o perfil e percepções dos visitantes do Parque Estadual da Serra do Conduru (PESC), a acessibilidade para o parque, a infraestrutura, e os principais elementos que atraem a visita das pessoas para essa UC do sul da Bahia. Usando questões abertas e objetivas nós registramos o perfil e as percepções de 35 visitantes. A acessibilidade, infraestrutura e atrativos do parque foram observados in loco. Participantes tinham alta escolaridade e visitavam frequentemente outras UCs. De acordo com nossos resultados os participantes não somente entendiam que estavam em uma área protegida como também esse fato influenciou sua escolha de visitar o local. Isso suporta argumentos que UCs podem atrair um público específico. Em adição, a opinião de parentes e amigos, e a divulgação pela internet foram influentes na escolha da visita. Desse modo, utilizar redes sociais para divulgação e aperfeiçoar o site do parque podem colaborar com o aumento do volume de visitação. A qualidade do serviço parece ter garantido a satisfação dos visitantes, apesar da pouca variedade de atrativos. Nossos resultados apontam que pequenas ações direcionadas a sinalização e oferta de informações podem melhorar o acesso e a experiência de lazer no parque. Por meio da observação da infraestrutura e número de participantes que se alojaram no PESC percebemos que o alojamento é um ponto forte cujo poderia ser mais bem aproveitado. 33 sugestões foram fornecidas pelos participantes acerca de melhorias na infraestrutura, atrativos, sinalização, divulgação, acesso, educação ambiental e captação de recursos e podem auxiliar a gestão do PESC e de outras UCs brasileiras. As sugestões dos visitantes demostram, principalmente, o desejo deles por maior variedade de atrativos e oportunidades de lazer no parque.

PALAVRAS-CHAVE: Atividade Física; Ecoturismo; Lazer; Planejamento; Recreação. 


\section{ABSTRACT}

Conservation Units (CUs) collaborate with biodiversity preservation, water resources maintenance and climate change mitigation. They also provide opportunities for pleasant experiences in contact with nature. In the present study, we analyzed the profile and perceptions of the visitors of the State Park of Serra do Conduru (SPSC), as well as the accessibility to the park, the quality of the infrastructure, and the main elements that attract people to visit this South Bahia CU. Using a mixed methodology, we registered visitors' profile and perception through a questionnaire filled in by 35 visitors. The accessibility, infrastructure, and elements that attract visitors to the park were observed in situ. Participants were well-educated and reported frequently visiting other CUs. According to our results, participants were aware of the fact that they were visiting a protected area, and this was one of their motivations for their visit. This result supports the idea that CUs can appeal to a specific audience. In addition, the opinions of relatives and friends about this specific $\mathrm{CU}$, together with information gathered through the Internet were essential when choosing to visit the park. Thus, using social networks to promote the park and improving the park's website could help to increase the number of visitors. The quality of the service seems to have guaranteed satisfaction of visitors, despite the low variety of attractions. In sum, our results point out that small actions aimed at signaling and providing information can improve access and leisure experience in the park. By observing the infrastructure and the number of participants who have accommodated in the SPSC we realize that the accommodation is a strong point which could be better utilized. 33 suggestions were provided by participants about improvements in infrastructure, attractiveness, signaling, divulgation, access, environmental education and fundraising and can assist the management of SPSC and other Brazilian CUs. The visitors' suggestions mainly show their desire for a greater variety of attractions and leisure opportunities in the park.

KEYWORDS: Physical Activity; Ecotourism; Leisure; Planning; Recreation.

\section{Introdução}

Evidências são cada vez mais conclusivas quanto aos impactos do estilo de vida atual no sistema terrestre. Desmatamento, perda da biodiversidade, mudanças climáticas e poluição são apenas alguns dos problemas que se não forem mitigados podem oferecer riscos a vida humana e de outras espécies (STEFFEN et al., 2015). A criação e manutenção de Unidades de Conservação (UCs) é uma importante ferramenta para garantia de condições de vida similares para as próximas gerações. No Brasil há dois grandes grupos de UCs, as de Proteção integral e as de Uso Sustentável. O primeiro grupo permite apenas o uso indireto dos recursos naturais, enquanto o segundo visa compatibilizar a conservação da natureza com uso sustentável de parte dos recursos. Essas unidades costumam ser criadas devido ao interesse e manifestação de órgãos públicos, sociedade civil e comunidade científica, em geral, sensibilizados pela necessidade de 
estabelecer mecanismos efetivos para proteção do patrimônio natural de certa região (DRUMOND; PEREIRA; FERNANDEZ, 2017).

O Parque Estadual da Serra do Conduru (PESC) é uma UC de Proteção Integral que permite o uso público de seu espaço, consistindo em local oportuno para experiências de lazer em contato com a natureza. Esse parque encontra-se em uma importante zona turística, e é caracterizado pela riqueza de sua flora. Devido à visitação turística a esse parque ser incipiente (GOMES, 2013), esforços têm sido direcionados ao aumento do volume de visitação, disponibilidade de atrativos e melhora na qualidade da visita. Ampliar a visitação significa aumentar a oferta de lazer em contato com a natureza à população e consequentemente o suporte a manutenção do parque (BROWNING et al., 2018; SOGA; GASTON, 2016). Em pesquisa recente, crianças que vivenciaram experiências de lazer em parques abertos tiveram seu sentimento de conexão com a natureza elevado e tenderam a concordar que a visita fez com que elas quisessem cuidar melhor do local (CRAWFORD; HOLDER; O'CONNOR, 2017).

Para aumentar o volume e a qualidade das visitas de parques, gestores necessitam de informações não somente acerca do perfil dos visitantes (idade, sexo, escolaridade) como também da sua percepção da experiência. Essa percepção envolve acesso (estrada e sinalização), qualidade do atendimento, disponibilidade de atrativos e infraestrutura. Outro ponto importante é entender o que influência as pessoas a visitarem essas áreas. Por exemplo, se o site de uma UC for o principal motivador para visita, investir esforços para melhoria desse site pode promover maior volume de visitação. Além disso, sugestões dos visitantes podem indicar os principais pontos em que a gestão deve focar. Nesse sentido, buscamos no presente estudo não somente analisar o perfil e as percepções dos visitantes do PESC, mas também o acesso, infraestrutura e atrativos desse local. Com isso, pretendemos colaborar com informações relacionadas ao planejamento dessa e de outras áreas protegidas brasileiras.

\section{Visitação em áreas protegidas}

Há notável interesse sobre os aspectos relacionados à visitação de áreas destinadas a conservação da natureza. Para ilustrar, busca rápida (em 26 de janeiro de 2018) sem limitação de ano no site da Revista Brasileira de Ecoturismo, utilizando o termo Unidade de Conservação gerou 76 resultados. Os tópicos investigados incluem a caracterização dos visitantes e suas percepções, e a descrição de áreas protegidas. Estudos indicam que adultos que realizam turismo em UCs, comumente chamados de ecoturistas, parecem em sua maioria compartilhar algumas características como ser jovem, ter alta escolaridade e renda (CAMPOS; VASCONCELOS; FÉLIX, 2011). Fonseca Filho e Ribeiro (2016), por exemplo, encontraram que visitantes do Parque Estadual da Serra do Rola-Moça eram em sua maioria jovens, utilizavam veículo próprio, se encontravam economicamente na classe $B$ e tinham boa escolaridade. 
Durante a realização de atividades em áreas protegidas, pessoas podem perceber diversos aspectos do ambiente. Mendes et al. (2017) reportaram que em visita ao Parque Nacional de Jericoacoara discentes de um curso de Turismo se atentaram a vegetação do local, presença de lixo e saneamento básico, ruídos e vandalismo. Essa percepção dos visitantes pode ser utilizada para identificar aspectos a serem aperfeiçoados por gestores visando à melhoria da qualidade da visita a áreas protegidas. Por exemplo, estudos têm encontrado que visitantes de áreas protegidas são geralmente preocupados com questões ligadas a proteção do meio ambiente (LARSON; USHER; CHAPMON, 2017). Isso indica que tanto as ações relacionadas à educação ambiental podem ser bem aceitas, como esses visitantes tendem a ter interesse em atividades ligadas a conservação da natureza.

Outro aspecto relevante é a caracterização de locais destinados a conservação. Afinal, características do ambiente podem influenciar tanto 0 perfil quanto as percepções dos visitantes. Por exemplo, um parque famoso pela oferta de atividades de aventura tende a atrair público mais jovem do que outro parque famoso por seu patrimônio histórico. Ainda, a percepção dos atrativos de um parque que oferta ampla variedade de atividades de lazer, tende a ser distinta da percepção dos atrativos de outro parque que oferece menor variedade dessas atividades. Nesse sentido, podemos destacar a apresentação de um estudo para criação de Unidade de Conservação Estadual de Proteção Integral, de categoria Monumento Natural, no estado de Minas Gerais (DRUMOND; PEREIRA; FERNANDEZ, 2017). Nesse estudo, são apresentadas diversas fotografias do local proposto para criação da UC, informações acerca do uso do solo e atividades com potencial turístico.

No presente estudo, nós buscamos integrar a análise do perfil e a percepção dos visitantes com a análise das características da UC, pois entendemos que a associação entre esses fatores incrementa a qualidade da investigação.

\section{Material e Métodos}

\section{Área de estudo}

O estudo foi realizado no Parque Estadual da Serra do Conduru PESC. De acordo com informações disponíveis em seu site (http://www.parquedoconduru.org/), o PESC é uma Unidade de Conservação de proteção integral, criada em 21 de fevereiro de 1997 pelo decreto n. 06227 do Governo do Estado da Bahia. A área do PESC tem 9.275 hectares, os quais abrangem os municípios de Ilhéus, Uruçuca e Itacaré (Figura 1). 


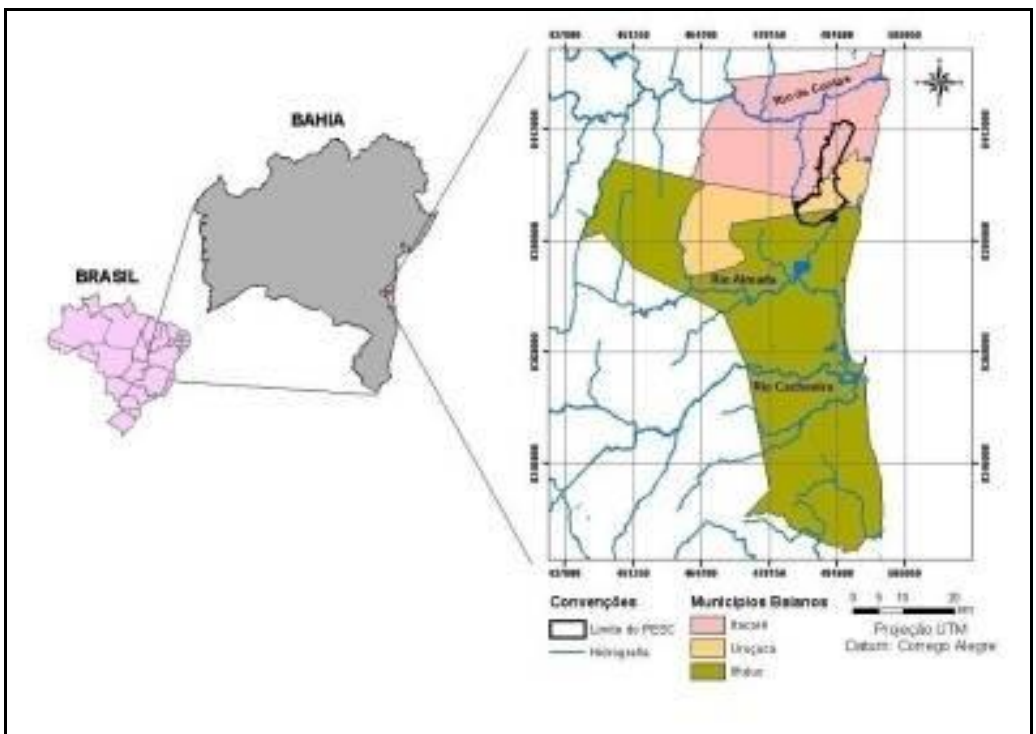

Figura 1: Localização do Parque Estadual da Serra do Conduru. Fonte: laboratório de geoprocessamento da IESB (2004 apud BAHIA, 2005)

Figure 1: Location of State Park of Serra do Conduru. Source: geoprocessing laboratory of the IESB (2004 apud BAHIA, 2005).

\section{Participantes e medida}

35 visitantes (15 mulheres e 20 homens) do PESC responderam ao questionário, com questões fechadas e abertas, adaptado de estudos prévios (SANTOS; AVILA, 2017; DUTRA et al., 2008). Cerca de $97 \%$ dos participantes tinham idade entre 18 e 60 anos. $71 \%$ tinham nível superior completo ou pós-graduação.

\section{Procedimento e análise dos dados}

$\mathrm{O}$ acesso, infraestrutura e atrativos do parque foram observados in loco. No período de setembro de 2016 a outubro de 2017, questionários foram preenchidos pelos visitantes com auxílio dos guarda-parques instruídos para a coleta. Todos os participantes responderam ao questionário no final da visita. As questões abertas e fechadas foram analisadas descritivamente. As respostas as questões abertas, análise da infraestrutura, acesso e atrativos do parque foram utilizadas para contextualização. O estudo recebeu parecer favorável do Comitê de Ética em Pesquisa com Seres Humanos da UESC, parecer $\mathrm{n}^{\circ}$ 1.386.889.

\section{Resultados}

Nós buscamos não somente descrever o perfil dos visitantes do PESC como também analisar suas percepções sobre o parque (p.ex., infraestrutura) e da visita (p.ex., satisfação com os atrativos). Consideramos que conhecer o PESC permitiria compreender melhor a percepção e perfil dos visitantes, desse modo, analisamos seu acesso, infraestrutura, atrativos, influências e 
serviços. O perfil da amostra junto com informações sobre o número de visitas ao PESC e outras UCs podem ser encontrados no Quadro 1. A percepção e uso dos visitantes relacionado ao acesso, infraestrutura, atrativos, influências e serviços são exibidos no Quadro 2.

Quadro 1: Perfil da amostra (p.ex., sexo, escolaridade) e informações sobre a visitação ao Parque Estadual da Serra do Conduru e outras unidades de conservação (número e porcentagem). Chart 1: Sample's profile (sex, education etc.) and information about visitation to State Park of Serra do Conduru and other conservation units (number and percentage).

\begin{tabular}{|c|c|}
\hline Variável & Perfil da amostra $(n=35)$ \\
\hline $\begin{array}{l}\text { Sexo } \\
\quad \text { Homens } \\
\text { Mulheres }\end{array}$ & $\begin{array}{l}20(57,14) \\
15(42,86)\end{array}$ \\
\hline $\begin{array}{l}\text { Escolaridade } \\
\text { Médio incompleto ou inferior } \\
\text { Médio completo } \\
\text { Superior incompleto } \\
\text { Superior completo } \\
\text { Especialização } \\
\text { Mestrado/Doutorado }\end{array}$ & $\begin{array}{c}3(8,56) \\
5(14,29) \\
2(5,71) \\
5(14,29) \\
6(17,14) \\
14(40,00)\end{array}$ \\
\hline $\begin{array}{l}\text { Idade } \\
18 \text { a } 25 \text { anos } \\
26 \text { a } 40 \text { anos } \\
41 \text { a } 60 \text { anos } \\
60 \text { anos ou mais }\end{array}$ & $\begin{array}{c}4(11,43) \\
19(54,29) \\
11(31,43) \\
1(2,86)\end{array}$ \\
\hline $\begin{array}{l}\text { Região } \\
\text { Brasil } \\
\text { Bahia } \\
\text { Outros estados }\end{array}$ & $\begin{array}{c}27(77,14) \\
20(57,14) \\
7(20,00)\end{array}$ \\
\hline $\begin{array}{c}\text { Estado Civil } \\
\text { Solteiro } \\
\text { Casado } \\
\text { Divorciado } \\
\end{array}$ & $\begin{array}{c}15(42,86) \\
18(51,43) \\
2(5,71)\end{array}$ \\
\hline $\begin{array}{l}\text { Número de visitas ao PESC } \\
\text { Primeira vez } \\
\text { Segunda vez } \\
\text { Mais de quatro vezes } \\
\end{array}$ & $\begin{array}{c}24(68,57) \\
5(14,29) \\
6(17,14) \\
\end{array}$ \\
\hline $\begin{array}{l}\text { Visitação a outras UCs } \\
\text { Sempre } \\
\text { Ocasionalmente } \\
\text { Raramente } \\
\text { Nunca }\end{array}$ & $\begin{array}{c}8(22,86) \\
19(54,29) \\
5(14,29) \\
3(8,57) \\
\end{array}$ \\
\hline
\end{tabular}

Nota: apenas alternativas que receberam resposta são exibidas. 
Quadro 2: Percepção e uso dos visitantes do Parque Estadual da Serra do Conduru (PESC) relacionado ao acesso, infraestrutura e atrativos, influências, serviços e satisfação (número e porcentagem). $N=35$.

Chart 2: Visitors' perception and use of the State Park of Serra do Conduru related to access, infrastructure and attractions, influences, services and

\begin{tabular}{|c|c|c|c|}
\hline Acesso & Infraestrutura e Atrativos & Influências para visitação & Avaliação dos serviços e satisfação \\
\hline 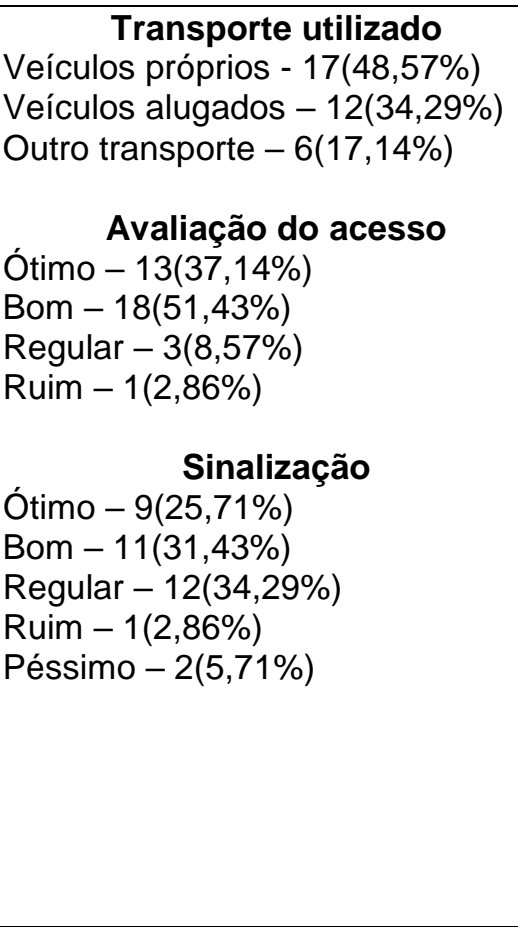 & 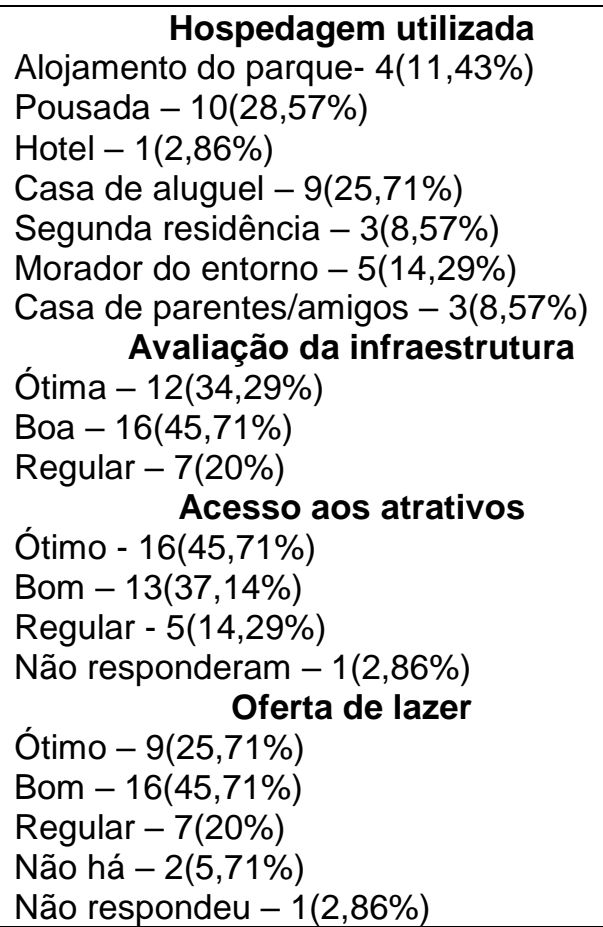 & \begin{tabular}{l}
\multicolumn{1}{c}{ Influências $^{*}$} \\
Amigos/parentes - 14(33,33\%) \\
Internet - $10(23,81 \%)$ \\
Televisão - $1(2,38 \%)$ \\
Revista/jornal $-2(4,76 \%)$ \\
Folheto avulso $-3(7,14 \%)$ \\
Outros - $12(27,57 \%)$ \\
O PESC ser uma Unidade de \\
Conservação influenciou a \\
$\quad$ sua visita? \\
Sim - $34(97,14 \%)$ \\
Não - $1(2,86 \%)$
\end{tabular} & $\begin{array}{l}\text { Serviço dos condutores } \\
\text { Ótimo - } 26(74,29 \%) \\
\text { Bom - } 3(8,57 \%) \\
\text { Regular }-1(2,86 \%) \\
\text { Não utilizaram }-5(14,29 \%) \\
\text { Serviço de atendimento } \\
\text { Ótimo - 30(85,71\%) } \\
\text { Bom - 3(8,57) } \\
\text { Regular - } 1(2,86 \%) \\
\text { Não respondeu - } 1(2,86 \%) \\
\quad \text { Atendimento as expectativas } \\
\text { Muito satisfeito - } 24(68,57 \%) \\
\text { Satisfeito - } 11(31,43 \%) \\
\quad \text { Intenção de retornar } \\
\text { Sim - } 35(100 \%) \\
\quad \text { Recomendaria visita } \\
\text { Sim - } 34(97,14 \%) \\
\text { Não - } 1(2,86 \%) \\
\quad \text { Avaliação da limpeza } \\
\text { Ótima - } 27(77,14 \%) \\
\text { Boa - } 7(20 \%) \\
\text { Não respondeu - } 1(2,86 \%)\end{array}$ \\
\hline
\end{tabular}

Nota: apenas alternativas que receberam resposta são exibidas. ${ }^{*}$ Os participantes podiam escolher mais de uma alternativa. 



\section{Perfil dos visitantes}

35 visitantes do PESC participaram da pesquisa. A maioria foi composta por homens $(57,14 \%)$, baianos $(57,14 \%)$, com nível superior completo ou pós-graduação $(71,4 \%)$. As faixas etárias preponderantes foram 26 a 40 anos (54,29\%) e 41 a 60 anos (31,43\%), 11,43\% tinham entre 18 e 25 anos e um participante mais que 60 anos. Finalmente, a grande maioria visitou o PESC pela primeira vez $(66,57 \%)$, cinco pessoas pela segunda vez $(14,29 \%)$ e seis pessoas visitaram mais de quatro vezes $(17,14 \%) .77,15 \%$ dos participantes afirmaram visitar outras UCs ocasionalmente ou sempre e apenas três participantes afirmaram nunca ter visitado outra UC.

\section{Acesso ao parque}

O PESC parece ser um local pouco conhecido inclusive na região, além de não ter seu trajeto e trilhas bem sinalizadas, o acesso a ele é relativamente complicado para quem não mora em seu entorno (Figura 2). 0 ramal - Rodovia Serra Grande/Uruçuca (BA-653) - que dá acesso ao Parque tem $13 \mathrm{~km}$ não pavimentados até a entrada, e não oferece acesso por meio de ônibus, sendo que carros pequenos podem ter dificuldade no percurso. Veículos próprios $(48,57 \%)$ ou alugados $(34,29 \%)$ foram os principais meios de transporte utilizados, somente seis pessoas relataram ter chegado de outra forma (17,14\%). 31 participantes acharam o acesso ao parque bom ou ótimo $(88,57 \%)$ e apenas quatro acharam regular ou ruim $(11,42 \%)$. Apenas $25,71 \%$ dos participantes acharam a sinalização do PESC ótima, 31,43\% acharam boa, $34,29 \%$ regular e três $(8,57 \%)$ avaliaram como ruim ou péssima.

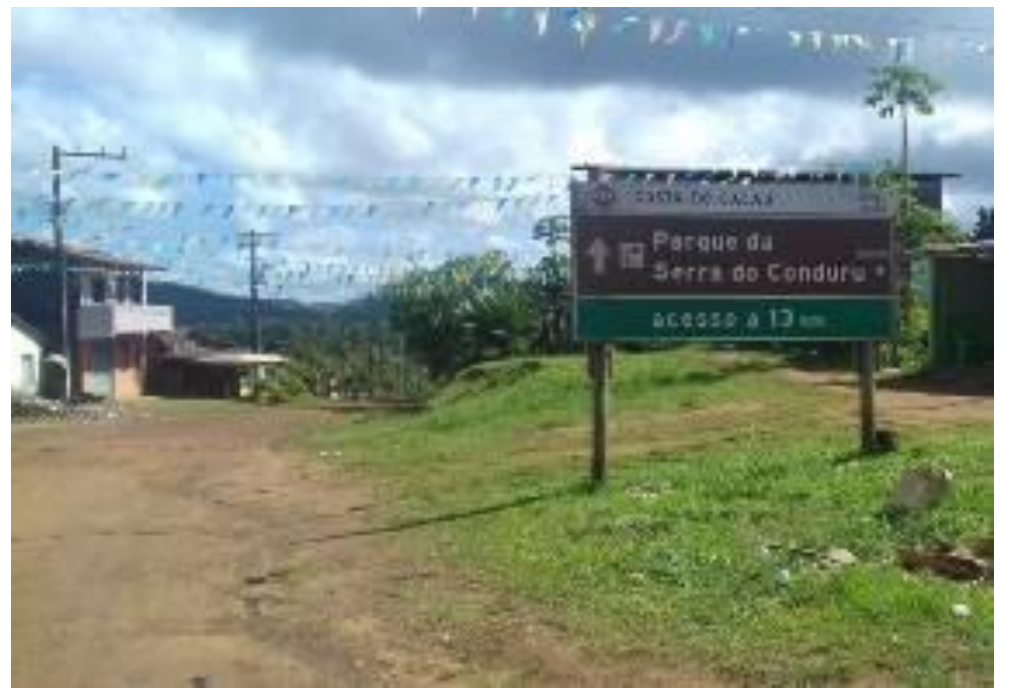

Figura 2: Placa de atrativo turístico alocada no início do acesso ao parque (BA-653).

Figure 2: Tourist attraction plate allocated at the beginning of the access to the park (BA-653).

Sociedade Brasileira de Ecoturismo. Rua Dona Ana, 138, Vila Mariana, São Paulo, SP - Brasil. E-mail: rbecotur@sbecotur.org.br; Tel. (55-11) 99195-7685. 


\section{Infraestrutura}

A infraestrutura do PESC incluía escritório, salas da sede de administração, alojamento, cozinha, refeitório e área destinada ao armazenamento de madeira apreendida. Tanto a sede quanto o alojamento eram de alvenaria, estavam em bom estado de conservação e com condições adequadas de higiene e limpeza. O alojamento dispõe de quatro quartos e quatro suítes com capacidade total para hospedar 48 visitantes (Figura 3 e 4). No térreo e no andar superior contém um total de quatro sanitários, dois masculinos e dois femininos, sendo apenas os de baixo adaptados para cadeirantes e crianças. Aqueles que se hospedam no PESC têm acesso à geladeira, fogão, micro-ondas, bebedouro e salão para reuniões. No entanto, não havia rampas de acessibilidade para cadeirantes ou adaptações para entrada na sede (Figura 5). Apenas quatro participantes utilizaram 0 alojamento do próprio parque $(11,43 \%)$ e cinco residiam no entorno (14,29\%), 20 participantes se hospedaram em pousada/hotel $(31,43 \%)$ ou casa de aluguel $(25,71 \%)$, três ficaram em casa de parentes $(8,57 \%)$ e três tinham uma segunda residência (8,57\%). 34,29\% dos visitantes acharam a infraestrutura do parque ótima, $45,71 \%$ boa e $20 \%$ regular.

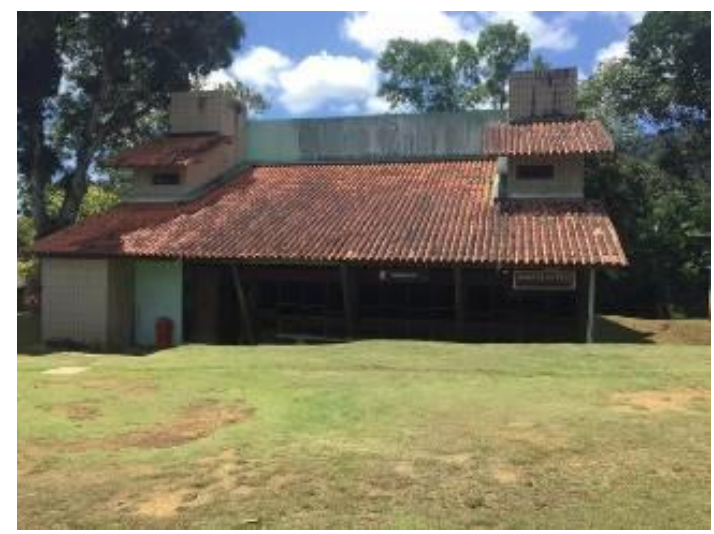

Figura 3: Alojamento do Parque Estadual da Serra do Conduru - área externa.

Figure 3: State Park of Serra do Conduru's lodging - external area.

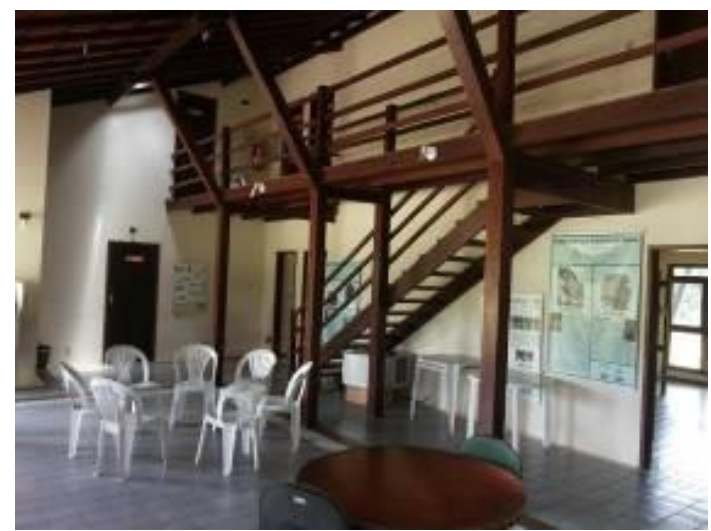

Figura 4: Alojamento do Parque Estadual da Serra do Conduru - área interna.

Figure 4: State Park of Serra do Conduru's lodging - internal area 


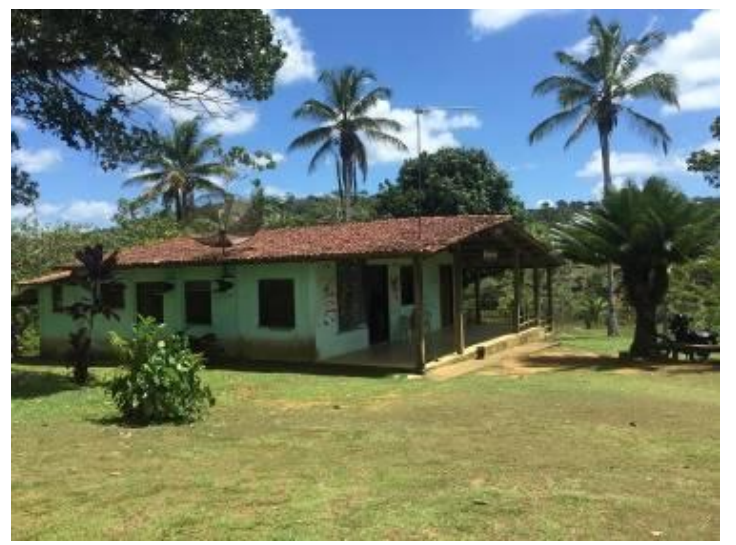

Figura 5: Sede da administração do Parque Estadual da Serra do Conduru.

Figure 5: Administration's headquarter of the State Park of Serra do Conduru

\section{Atrativos}

Duas trilhas ecológicas são os principais atrativos do PESC para os visitantes. O nível de dificuldade das trilhas é semelhante e relativamente fácil. No entanto, uma trilha possuía acesso um pouco mais difícil, mata mais fechada e apresentava dificuldades para sua realização devido à carência de manutenção (p.ex., poda). Apenas algumas espécies da flora estavam identificadas ao longo das trilhas, e o encontro com animais era raro. Nome, indicação sobre duração e grau de dificuldade das trilhas puderam ser encontrados apenas no site do PESC. Não obstante, $45,71 \%$ dos participantes avaliaram 0 acesso aos atrativos do parque como ótimos, $37,14 \%$ como bons, $14,29 \%$ como regulares, uma pessoa não respondeu. Por outro lado, apenas nove pessoas $(25,71 \%)$ acharam a oferta de lazer ótima, $16(45,71 \%)$ boa, sete pessoas (20\%) regular, duas pessoas afirmaram que não há oferta de lazer $(5,71 \%)$ e uma não respondeu $(2,86 \%)$.

\section{Influências para visitação}

Para aumentar a visitação do PESC é importante conhecer o que levou as pessoas a visitá-lo. Quatorze entrevistados foram influenciados a visitar 0 parque por amigos e familiares (33,33\%) e 10 pela internet $(23,81 \%)$. Televisão influenciou uma pessoa, revista e jornal duas e folhetos avulsos três, 12 participantes $(25,57 \%)$ afirmaram ter sido influenciados de outra forma. Não somente todos os participantes declararam ter consciência de estar em uma UC, como apenas um afirmou que isso não foi importante para escolha de visitar o parque.

\section{Avaliação dos serviços e satisfação}

Finalmente, em vista de perceber o que poderia melhorar a qualidade da visitação no PESC, nós analisamos a avaliação dos serviços pelos participantes. Tanto o serviço dos condutores do parque como o atendimento foram bem qualificados. Somente, uma pessoa considerou ambos os serviços regulares, e mais de $80 \%$ acharam bom ou ótimo. 
Cinco participantes não utilizaram o serviço dos condutores $(14,29 \%)$ e uma pessoa não respondeu sobre o serviço de atendimento. 34 participantes $(97,14 \%)$ acharam a limpeza do parque boa ou ótima e um participante não respondeu. Todos os participantes se declararam muito satisfeitos $(68,57 \%)$ ou satisfeitos $(31,43 \%)$ quanto o atendimento as suas expectativas. Apenas um afirmou que não recomendaria a visita, e todos declararam ter intenção de retornar ao PESC.

\section{Sugestões}

O maior número de sugestões foi direcionado a oferta de atrativos, infraestrutura e sinalização. Os visitantes também notaram a necessidade de maior divulgação, educação ambiental e criação de taxa para melhoria do parque (Quadro 3).

Quadro 3: Sugestões dos participantes (categorias, total e exemplos) para melhorias no

Parque Estadual da Serra do Conduru.

Chart 3: Participants' suggestion (categories, total and examples) for improvement on State

Park of Serra do Conduru.

\begin{tabular}{|c|c|c|}
\hline Categoria & Total & Exemplos de sugestões \\
\hline Divulgação & 4 & $\begin{array}{l}\text { - Utilizar fotografias da fauna e flora; } \\
\text { - disponibilizar folder e livros com nome das espécies; } \\
\text {-criar folhetos com mapas } \\
\text { - ampliar divulgações em agências e em Serra Grande. }\end{array}$ \\
\hline $\begin{array}{l}\text { Atrativos } \mathrm{e} \\
\text { Infraestrutura }\end{array}$ & 22 & $\begin{array}{l}\text { - Ampliar atrativos para crianças; } \\
\text { - ampliar área de lazer; } \\
\text { - criar centro de visitantes; } \\
\text {-criar loja para atrativos da região; } \\
\text { - criar programa para observação de aves; } \\
\text { - identificar melhor a fauna e flora; } \\
\text { - melhorar conexão com a internet; } \\
\text { - ampliar guardas para visitas noturnas; } \\
\text { - falta de água potável; } \\
\text { - plano de visitação; } \\
\text {-melhorar o mirante; } \\
\text {-identificar níveis de dificuldade e tempo dos percursos nas } \\
\text { trilhas. }\end{array}$ \\
\hline Sinalização & 5 & $\begin{array}{l}\text {-Sinalizar a nova trilha; } \\
\text { - sinalizar a trilha da mata; } \\
\text { - sinalizar melhor desde a BA- } 001 \text {. }\end{array}$ \\
\hline $\begin{array}{l}\text { Educação } \\
\text { ambiental }\end{array}$ & 1 & - Coibir escrita nas árvores. \\
\hline $\begin{array}{l}\text { Captação de } \\
\text { recursos }\end{array}$ & 1 & - Criar taxas para reverter em melhorias ao parque. \\
\hline
\end{tabular}

Nota: mais de uma sugestão por participante. 


\section{Discussão}

Nós não somente contribuímos com estudos anteriores que se esforçaram em descrever o perfil dos visitantes de UCs, como também analisamos a percepção dos visitantes, considerando o acesso, infraestrutura e atrativos do parque. Em adição, os próprios participantes sugeriram melhorias para aperfeiçoar a experiência no PESC, sugestões que podem servir a outros parques nacionais.

\section{Perfil dos visitantes e da amostra}

É interessante destacar que a amostra se revelou altamente educada e experiente com relação à visitação a UCs. Mais de $70 \%$ possuía nível superior ou pós-graduação e quase $80 \%$ relataram visitar outras unidades sempre ou ocasionalmente. Coletivamente, os 35 entrevistados na pesquisa seguem o perfil geral dos visitantes adultos de UCs (CAMPOS; VANCONCELOS; FELIX, 2011; FONSECA FILHO; RIBEIRO, 2016), isto é, indivíduos com alta escolaridade e boas condições econômicas. Esses dados indicam não somente que pode existir um perfil de visitantes a UCs, como também que os participantes podem ter visão crítica e capacidade para comparar o PESC com outros parques e sugerir melhorias.

\section{Acesso}

Não apenas o acesso ao PESC pode ser considerado difícil para quem não vive em seu entorno, como também o percurso poderia ser mais bem sinalizado. Inclusive, foi sugerido por um participante da pesquisa que a sinalização para o parque deveria ser aperfeiçoada desde antes de sua entrada, na rodovia BA-001. A sinalização também necessita ser aprimorada no caminho até a sede do parque, assim como é preciso informar ao visitante que a área está aberta à visitação. Um dos visitantes relatou "quase voltamos achando que estava fechado". Essa dificuldade de acesso e sinalização pode estar limitando o perfil dos visitantes, por exemplo, cerca de $83 \%$ dos participantes afirmaram ter utilizado veículo próprio ou alugado e apenas $17 \%$ outros meios de transporte. Esse número é ainda mais notável, se observado que cinco participantes (14,3\%) eram moradores do entorno. Considerando que a grande maioria utilizou veículos ou moravam próximo ao local de visitação, é compreensível que quase $90 \%$ dos participantes tenham achado - acesso bom ou ótimo. Por outro lado, quase $45 \%$ dos participantes consideraram a sinalização regular, ruim ou péssima. Esses dados indicam que o acesso necessita de melhorias, mas que, no entanto, a sinalização é um problema mais urgente. Essa sinalização engloba não somente a orientação até o PESC como também informações sobre os atrativos. Alguns visitantes sugeriram melhorar a sinalização das trilhas e identificar os níveis de dificuldade e o tempo de percurso. 


\section{Infraestrutura}

A maioria dos participantes achou a infraestrutura ótima ou boa, mas cerca de $20 \%$ achou regular. Apesar de não ter havido sugestões quanto à melhoria da acessibilidade, observamos que algumas modificações podem ser realizadas para facilitar o acesso para pessoas com deficiência (p.ex., rampas de acesso). Essa garantia de acessibilidade não somente melhoraria as condições de visitação como poderia atrair novos visitantes. Outro ponto interessante é que apesar do PESC possuir capacidade para hospedar 48 pessoas, apenas quatro participantes $(11,4 \%)$ utilizaram o alojamento. Pela observação in loco e avaliação dos participantes foi possível perceber que a higiene e limpeza do parque são ótimas. Em adição, não somente a hospedagem é gratuita como também o parque oferece suporte (p.ex., fogão, geladeira) aos que ficam alojados. Diante dessas condições, é possível afirmar que o alojamento é um ponto forte para melhorar a visitação, que, no entanto, tem sido pouco aproveitado. Isso pode ser aprimorado com divulgação dessas qualidades ou facilitação no processo de alojamento. Infraestrutura, junto com atrativos, foi à categoria que recebeu o maior número de sugestões dos visitantes que participaram do estudo (ver Quadro 1). As sugestões em geral exibem o desejo dos visitantes por outras experiências de lazer além das oferecidas, mas em alguns casos referem-se a necessidades básicas como água potável, ou estruturais como acesso à internet.

\section{Atrativos}

No período da visita, duas trilhas semelhantes em duração e dificuldade eram os principais atrativos do parque. No entanto, informações sobre essas trilhas (p.ex., duração, dificuldade) não puderam ser facilmente acessadas pelos visitantes no local da visita. Ficou claro durante o estudo que existe uma necessidade de ampliação da oferta de atividades de lazer no PESC. Apenas $25,7 \%$ dos participantes acharam a oferta de lazer ótima e diversas sugestões foram direcionadas à criação de outras experiências, além da realização de trilhas. Entre as principais sugestões dos participantes estão: ampliar atrativos para crianças, criar centros de visitantes, criar loja com atrativos da região, identificar melhor a fauna e a flora. Apesar de por questões éticas menores de 18 anos não terem participado do estudo, 0 PESC recebe algumas excursões de crianças e adolescentes por meio de parcerias com escolas (GOMES, 2013). A criação de centros de visitantes ou de loja com atrativos se associa com a necessidade de o parque melhorar sua capitação de recursos. Enquanto tais mudanças são mais complexas, a melhor identificação da fauna e da flora pode ser realizada com relativa facilidade. Diversas pesquisas científicas têm sido realizadas no parque. Com algum esforço, informações relevantes aos visitantes sobre a fauna e a flora poderiam ser compiladas e compartilhadas tanto pelo site como por pôster ou panfletos no local. 


\section{Influências para visitação}

Aumentar o número de visitações é um dos principais objetivos do PESC. Nesse sentido, entender o que influenciou a visitação das pessoas é fundamental. A maioria dos participantes afirmou ter sido influenciada por amigos ou parentes, e boa parte pela internet ou outras mídias. Adicionalmente, o fato do PESC ser uma UC também influenciou a visitação. Esses resultados indicam que melhorar a qualidade da visitação tende a aumentar o número de visitas, pois boa parte da divulgação é feita "boca a boca". A internet influenciou cerca de $24 \%$ dos participantes. Esse meio apresenta diversas oportunidades de divulgação com baixo custo. Tanto as redes sociais podem ser melhor exploradas como 0 site pode ser aperfeiçoado. Para ilustrar, o site do Parque Estadual Serra do Mar (PESM) pode servir como inspiração. Neste site (http://www.parqueestadualserradomar.sp.gov.br/pesm/), não somente podemos conhecer o PESM utilizando um mapa iterativo do local, como também diversas informações estão disponíveis sobre a biodiversidade desse parque. Além disso, em seu site é destacada a sua considerável variedade de atrativos.

Entre as sugestões dos visitantes do PESC para divulgação estavam: utilizar fotografias da fauna e da flora, disponibilizar folder e livro com o nome das espécies, criar folhetos com mapas, ampliar divulgações em agências e em Serra Grande. As três primeiras estratégias de divulgação se relacionam fortemente e podem aprimorar a experiência de visitação. Ou seja, fotografias da fauna e da flora podem ser tanto utilizadas para divulgação como para informar as pessoas quanto aos atrativos. O mesmo ocorre para disponibilização de folders e mapas. Como sugerido, os gestores do PESC poderiam analisar a possibilidade de parcerias com agências de turismo e de maior divulgação em Serra Grande, município próximo ao parque. Por fim, é importante ressaltar no processo de divulgação que o PESC é uma UC, já que esse fato pode atrair visitantes.

\section{Avaliação dos serviços}

A avaliação dos serviços indica que apesar das suas limitações, o PESC oferece atendimento e serviço de condutores de qualidade. Todos os participantes relataram intenção de revisitar e apenas um afirmou que não pretende indicar o PESC. Além disso, as expectativas foram atendidas de modo satisfatório ou muito satisfatório. Nesse sentido, é importante que no processo de mudanças que o parque se encontra, atenção seja dada a manutenção da qualidade dos serviços, de modo que os visitantes continuem satisfeitos, com intenção de retornar e recomendar a visita. $O$ que pode se apresentar como um desafio à medida que o volume de visitação aumente. 


\section{Conclusão}

Considerável esforço tem sido dedicado para melhorar a qualidade da experiência e ampliar a visitação no PESC. O presente estudo não se limita, mas visa também colaborar com esse esforço. Ampliar a qualidade e volume de visitação significa não somente oportunizar a população vivências associadas à qualidade de vida e bem-estar como também aumentar 0 suporte a áreas de conservação da natureza.

O PESC apresenta um perfil de visitação característico de diversas outras UCs, isto é, o visitante padrão tem alta escolaridade e possui boas condições econômicas.

Forças e fraquezas puderam ser observadas no parque investigado. Infraestrutura, acesso e atrativos são as principais limitações. Enquanto mudanças na infraestrutura podem ser mais complexas, pequenas ações direcionadas a sinalização e oferta de informações podem melhorar o acesso e a experiência de lazer no PESC. A qualidade do serviço (p.ex., atendimento, condutores, limpeza) revelou-se o ponto mais forte desse parque. Apesar da pouca variedade de atrativos, visitantes do parque que participaram do estudo relataram ter suas expectativas atendidas e terem intenção de revisitar.

Análise das influências para visitação indicou que à medida que a qualidade da visita melhorar o número de visitantes tende a aumentar, pois a maior fonte de influência para visitação foi à sugestão de amigos e parentes. A internet também deve ser observada com atenção, pois influenciou boa parte dos visitantes. Nesse sentido, o uso de redes sociais e a melhoria do site podem colaborar para divulgação. Vale observar que quase $80 \%$ dos participantes indicaram visitar outras UCs sempre ou ocasionalmente. Desse modo, mesmo que outras UCs não tenham tantos atrativos (como o PESC), investir na qualidade dos serviços e utilizar a internet como meio de divulgação pode ser efetivo para satisfação do visitante e aumento da visitação.

Finalmente, 33 sugestões relacionadas à divulgação, atrativos e infraestrutura, sinalização; educação ambiental e captação de recursos foram disponibilizadas pelos participantes (Quadro 1) e podem ser aproveitadas por gestores do PESC e de outras áreas protegidas. É possível perceber que as sugestões dos participantes expressam seu desejo por melhor infraestrutura, sinalização e maior variedade de atrativos e oportunidades lúdicas.

\section{Referências}

BAHIA. Plano de Manejo do Parque Estadual da Serra do Conduru. 2005. Disponível em: <http://www.parquedoconduru.org/images/ENCARTE 2.pdf>. Acesso em: 26 jan. 2018.

BROWNING, M.H.E.M. et al. Factors that contribute to community members' support of local nature centers. Environmental Education Research, v. 24, n. 3, 326-342, 2018. 
CAMPOS, R.F.; VASCONCELOS, F.C.W.; FÉLIX, L.A.G. A Importância da Caracterização dos Visitantes nas Ações de Ecoturismo e Educação Ambiental do Parque Nacional da Serra do Cipó/MG. Turismo em análise, v. 22, n. 2, p. 397-426, ago. 2011.

CRAWFORD, M.R., HOLDER, M.D.; O'CONNOR, B.P. Using Mobile Technology to Engage Children With Nature. Environment and Behavior, v. 49, n. 9, p. 959-984. 2017.

DRUMMOND, B.; PEREIRA, P.A.; FERNANDES, A.S. O olhar para o potencial turístico como elemento agregador em estudos de criação de Unidade de Conservação. Caderno Virtual de Turismo. Rio de Janeiro, v. 17, n. 1, p. 16-29, abr. 2017.

DUTRA, V.C.; SENNA, M.L.G.S.; FERREIRA, M.N.; ADORNO, L.F.M. Caracterização do perfil e da qualidade da experiência dos visitantes no Parque Estadual do Jalapão, Tocantins. Caderno Virtual de Turismo. v.8, n.1, p. 104-117. 2008.

FONSECA FILHO, R.E.; RIBEIRO, G.S. Perfil do geoturista do Parque Estadual da Serra do Rola-Moça (MG). Revista Brasileira de Ecoturismo, São Paulo, v. 9, n. 3, p.471-496, ago./out. 2016.

GOMES, D.A.Q. Análise da visitação pública no Parque Estadual da Serra do Conduru (PESC) - BA. Dissertação (Mestrado em Desenvolvimento Regional e Meio Ambiente). Universidade Estadual de Santa Cruz, Ilhéus, 2013.

LARSON, L.R.; USHER, L.E.; CHAPMON, T. Surfers as Environmental Stewards: Understanding Place-protecting Behavior at Cape Hatteras National Seashore. Leisure Sciences, p. 1-24. 2017. Disponível em: <http://www.tandfonline.com/doi/abs/10.1080/01490400.2017.1305306>

Acesso em: 25 jan. 2018

MENDES, FL.S. et al. O Parque Nacional de Jericoacoara na percepção dos discentes do curso de Turismo da UFPA. Revista Brasileira de Ecoturismo, São Paulo, v. 10, n. 1, p. 49-63, fev./abr. 2017.

SANTOS, M.S.; AVILA, M.A. Planejamento participativo: uma análise do turismo de Uruçuca (BA) a partir da ótica dos residentes. Caderno Virtual de Turismo, v. 17, p. 30-45, 2017.

SOGA, M.; GASTON, K. Extinction of experience: the loss of human-nature interactions. Frontier in Ecology and the Environment, v. 14, n. 2, p. 94101, 2016.

STEFFEN, W. et. al. Planetary boundaries: Guiding human development on a changing planet. Science. v. 347, n. 6223, p. 736-746, fev. 2015.

Nota: Claudio Damião Rosa recebeu bolsa de estudo da Fundação de Amparo à Pesquisa do Estado da Bahia (FAPESB). 
Marco Aurélio Avila: Universidade Estadual de Santa Cruz, Ilhéus, BA, Brasil. E-mail: mavila1000@gmail.com

Link para o currículo Lattes: http://lattes.cnpq.br/6955720245737112

Claudio Damião Rosa: Universidade Estadual de Santa Cruz, Ilhéus, BA, Brasil.

E-mail: claudio2008ilheus@hotmail.com

Link para o currículo Lattes: http://lattes.cnpq.br/9878868630424353

Data de submissão: 27 de janeiro de 2018

Data de recebimento de correções: 30 de maio de 2018

Data do aceite: 30 de maio de 2018

Avaliado anonimamente 